\title{
PENGELOLAAN DAN PENGEMBANGAN BANK SAMPAH BERBASIS KEMANFAATAN DAN TEKNOLOGI INFORMASI (DI MANUKAN KULON TANDES SURABAYA)
}

\author{
M. Hasan Abdullah', Nurwahyudi Widhiyanta ${ }^{2}$ \\ ${ }^{1}$ Teknik Industri Universitas Wijaya Putra \\ ${ }^{2}$ Teknik Informatika Universitas Wijaya Putra \\ ${ }^{1}$ mhasanabdullah@uwp.ac.id, ${ }^{2}$ Nurwahyudi.widhiyanta@uwp.ac.id
}

\begin{abstract}
Abstrak
Keberadaan Bank Sampah sangat membantu dalam mengurangi volume sampah dan dapat menunjang kehidupan ekonomi serta sosial masyarakat sekitar. Namun beberapa kendala muncul seiring berjalannya waktu. Sehingga eksistensi Bank Sampah ini mulai terancam. Beberapa persoalan muncul disebabkan antara lain karena kurangnya kesadaran dan motivasi, pengetahuan dalam pemilahan sampah, pengelolaan yang kurang efektif serta masih minimnya pengembangan dan pemanfaatan hasil Bank Sampah yang bisa dirasakan oleh masyarakat. Tujuan Program Pemberdayaan Masyarakat ini adalah untuk meningkatkan peran serta masyarakat dalam kegiatan Bank Sampah dan meningkatkan manfaat dari Bank Sampah. Sehingga Bank Sampah mempunyai daya tarik dan dapat memotivasi warga untuk lebih aktif dalam kegiatan Bank Sampah. Kegiatan dilaksanankan dengan pendekatan yang melibatkan masyarakat secara langsung sebagai subyek dan obyek pelaksanaan kegiatan pengabdian kepada masyarakat melalui penyuluhan, pelatihan dan pendampingan pada mitra. Wujud dari program pengabdian ini adalah munculnya inovasi pemanfaatan Bank Sampah seperti kerajinan berbahan sampah kering, program kursus berbayar sampah, tabungan serta program aplikasi untuk transaksi Bank Sampah.
\end{abstract}

Kata Kunci : bank sampah, pengabdian masyarakat

\section{PENDAHULUAN}

Saat ini bank sampah menjadi salah satu program andalan yang digulirkan oleh kementrian lingkungan hidup dan merupakan salah satu kriteria penilaian untuk kota Adipura. Beberapa alasan yang menjadikan bank sampah ini menjadi pilihan adalah karena mempunyai manfaat terhadap aspek ekonomi, lingkungan dan sosial. Surabaya sebagai salah satu kota Adipura berupaya menerapkan konsep pengelolaan sampah dengan memberdayakan masyarakat Kota Surabaya melalui program bank sampah. Dengan penerapan bank sampah ini secara tidak langsung akan terbentuk green community yang mengelola sampah anorganik rumah tangga untuk mendukung Green City. Sehingga Surabaya terpilih menjadi tiga kota terbaik dunia untuk kategori Global Green City.

Namun untuk mewujudkan bank sampah yang sustainable tidak mudah sebab sangat bergantung pada keaktifan pengurus dan komunitas dalam mengelola bank sampah. Beberapa bank sampah yang dikelola RW 09 di Wilayah Manukan Kulon dan di wilayah RW 01 Banjarsugihan Kecamatan Tandes Kota Surabaya hanya mampu berjalan beberapa bulan dan tidak berkembang. Secara umum ada tiga aspek yang menjadi 
penyebabnya, yaitu aspek manajemen, aspek teknologi dan aspek sosial ekonomi.

Permasalahan yang ada pada mitra Bank sampah ini diantaranya. 1) Pengetahuan dalam memilah sampah masih minim dimiliki oleh petugas dan nasabah. Serta pemilahan yang tidak didukung sarana yang memadai. Hal ini menyebabkan pemilahan dan pencatatan hasil setoran sampah menjadi tidak efektif dan efisien. 2) Pembukuan atau pencatatan hanya mengandalkan Buku tabungan saja sehingga ketika buku ini hilang atau rusak maka pengurus sulit untuk melakukan pemeriksaan ulang. 3) Pemanfaatan atau pengembangan bank sampah belum maksimal. Hanya beberapa yang bisa diolah untuk menjadi produk daur ulang yang bernilai ekonomis. Dampak sosial lainnya belum tersentuh sehingga kurang memotivasi mereka untuk aktif di bank sampah.

\section{METODE}

Metode pelaksanaan pada program pemberdayaan masyarakat untuk pengelolaan dan pengembangan bank sampah ini dilakukan dengan melibatkan masyarakat secara langsung sebagai subyek dan obyek pelaksanaan kegiatan melalui penyuluhan, pelatihan serta pendampingan. Kegiatan penyuluhan dilakukan untuk mensosialisasikan 3R (reduce, reuse, recycle) pada masyarakat agar lebih menyadari tentang budaya peduli lingkungan serta berperan aktif dalam program bank sampah yang ada. Pengetahuan tentang jenis-jenis sampah anorganik, pemanfaatan serta pengetahuan jenis sampah yang berbahaya. Kegiatan pelatihan ditujukan untuk memberikan ketrampilan daur ulang sampah, serta aplikasi pencatataan setoran dan tabungan bank sampah. Pendampingan dilakukan untuk memastikan program yang dilakukan sesuai dengan tujuan dan dapat berjalan secara kontinyu. Pendampingan akan dilakukan secara berkala dan sewaktu-waktu apabila dibutuhkan oleh mitra.

\section{HASIL DAN PEMBAHASAN}

\section{Kegiatan penyuluhan}

Kegiatan awal ini dilakukan untuk menumbuhkan kesadaaran dan kepedulian masyarakat terhadap lingkungan. Kegiatan ini diselenggarakan bekerja sama dengan Kelompok PKK dan Ketua RT setempat. Karena sebagian besar pengurus atau penggerak Bank sampah adalah dari kalangan ibu-ibu. Selain itu, program ini juga melibatkan remaja di sekitar lokasi yang tergabung dalam Remaja Masjid.

Materi yang disampaikan dalam penyuluhan dan diskusi adalah terkait dengan pengetahuan dan pengelolaan sampah serta isu-isu lingkungan saat ini. Dengan mengetahui jenis sampah maka akan memudahkan untuk memilah dan meningkatkan harga sampah. Sampah yang masih tercampur mempunyai nilai yang lebih rendah dibanding sampah yang sudah terpilah. Dengan penyuluhan ini, masyarakat juga lebih termotivasi untuk mengimplementasikan prinsip $3 \mathrm{R}$ dilingkungan tempat tinggal. Sehingga volume sampah yang terbuang akan berkurang dengan drastis. Kegiatan penyuluhan dan praktek pemilahan jenis sampah terlihat pada gambar 1 dan gambar 2 .

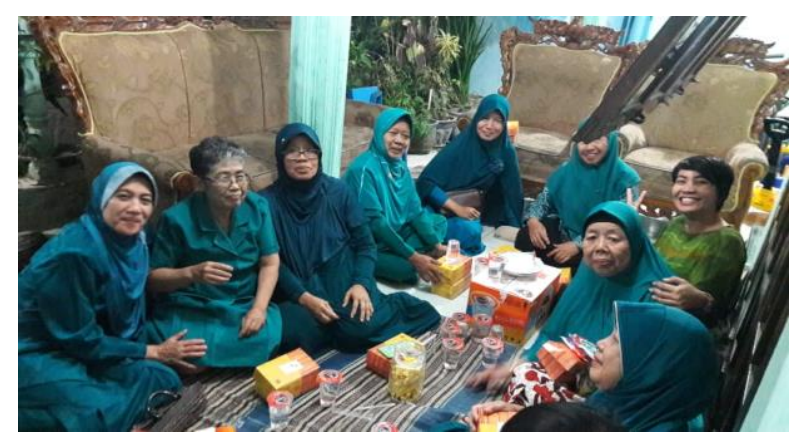

Gambar 1. Penggerak PKK dalam kegiatan
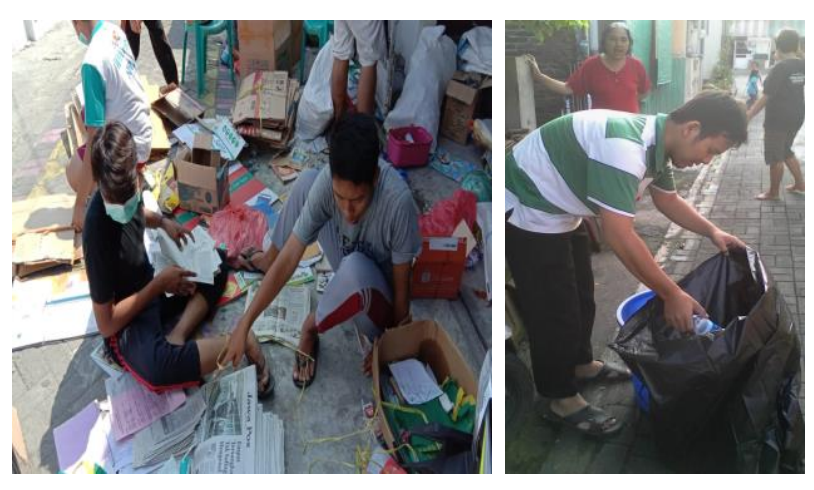
Gambar 2. Praktek memilah di Bank Sampah dan rumah warga

\section{Kegiatan pelatihan}

Pelatihan dilakukan bersama Mitra Bank Sampah dan bekerja sama dengan fasilitator untuk memberikan contoh dan cara membuat produk dari sampah plastik. Berbagai produk daur ulang berhasil diproduksi oleh ibu-ibu PKK dengan memanfaatkan sampah plastik dari Bank Sampah. Produk hasil daur ulang ini dijual melalui grup di medsos.

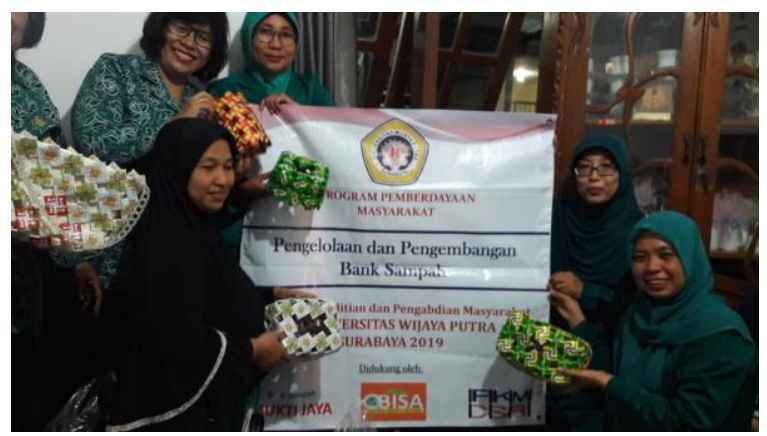

Gambar 3. Pelatihan daur ulang sampah kering

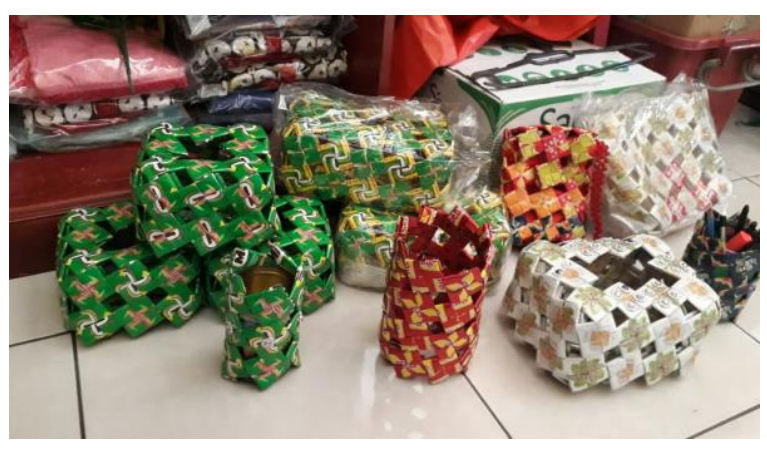

Gambar 4. Aneka produk hasil daur ulang

Selain pelatihan daur ulang sampah, pelatihan juga diberikan kepada Mitra dalam menggunakan aplikasi pembukuan untuk bank sampah. Software sederhana ini dibuat untuk membantu pencacatan dan pelaporan terkait transaksi bank sampah. Dengan adanya aplikasi ini, petugas bank sampah mempunyai database nasabah, data tabungan, laporan keluar-masuk dan data lainnya yang tersimpan baik dan sewaktuwaktu bisa digunakan dengan cepat dana aman.
Software untuk bank sampah tersebut dikembangkan oleh tim pengabdian dengan menyesuaikan kebutuhan yang ada pada Mitra. Software ini dapat dipasang pada laptop atau PC yang dimiliki oleh petugas. Tata cara pengoperasian diberikan pada bagian admin bank sampah. Nagian utama dari aplikasi ini adalah Master Data, Transaksi dan Laporan.

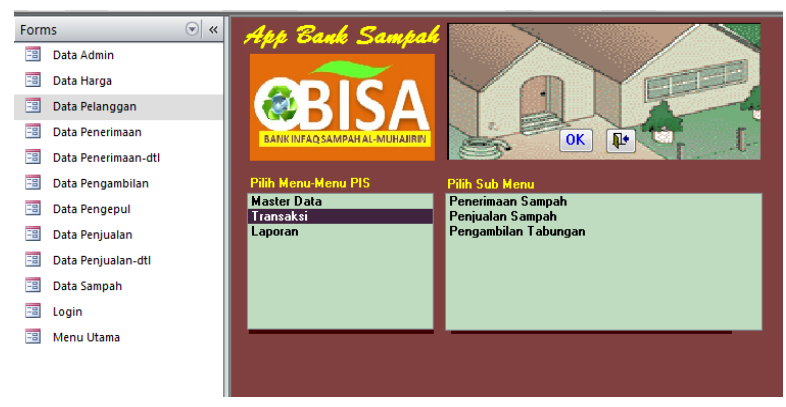

Gambar 5. Halaman Muka Aplikasi Bank Sampah

\section{Kegiatan pendampingan}

Pendampingan dilakukan pada mitra selama kegiatan dan setelah kegiatan agar dampak dari kegiatan bisa sesuai dengan tujuan. Pendamping ikut serta dalam aktifitas di bank sampah. Dengan demikian kendala-kendala yang ada dapat diketahui secara langsung dan dicarikan solusi.

Pada kegiatan ini, keaktifan pengurus bank sampah sangat dibutuhkan. Karena pengurus sebagai penggerak utama dan menjadi motivasi dari nasabah atau masyarakat. Beberapa hal yang tampak ada perubahan selama pendampingan. Mitra dapat melakukan pemilahan dan melakukan tata letak sampah dengan baik sesuai dengan jenisnya. Selain itu masyarakat sudah bisa melakukan pemilahan sampah sendiri di rumah sebelum disetorkan ke bank sampah. Hal ini akan meningkatkan produktifitas bank sampah. 


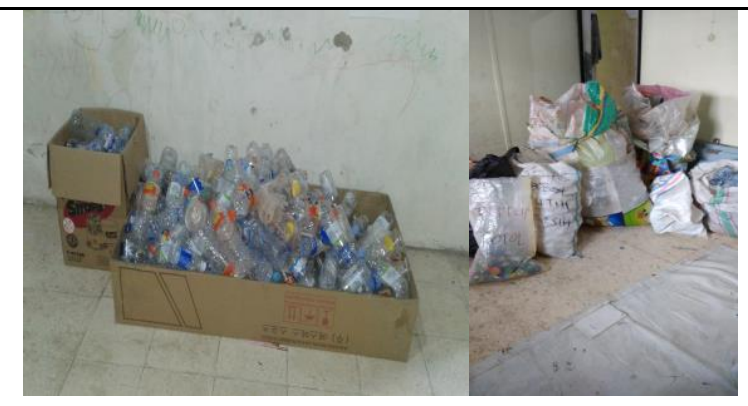

Gambar 6. Sampah yang sudah terpilah

\section{Pengembangan Bank Sampah}

Bank sampah mempunyai rencana pengembangan dalam aktifitasnya. Hal ini diperlukan agar keberadaan bank sampah dapat lebih dirasakan oleh masyarakat. Sehingga masyarakat menjadi lebih termotivasi dan aktif dalam kegiatan bank sampah. Beberapa rencana pengembangan telah dibuat oleh mitra bersama Tim, di antaranya membuka tempat belajar untuk anak-anak sekitar lokasi bank. Tempat belajar ini dinamakan "rumah pintar". Sebagai biaya operasional diambilkan dari sampah yang disetorkan ke bank.

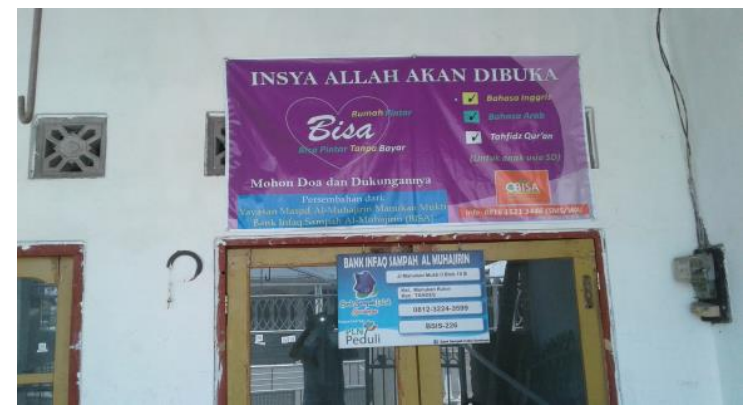

Gambar 7. Sampah yang sudah terpilah

Selain itu, untuk meningkatkan produktifitas dan meningkatkan efisiensi, bank sampah mitra merencakan untuk mendesain mesin pengcacah plastik. Dengan adanya mesin ini, harga sampah akan naik 40-50\% dari harga awal serta volume sampah dalam Gudang akan berkurang, karena ukuran plastic sudah berubah menjadi kecilkecil. Hal ini bisa menghemat tempat penyimpanan barang dan menaikkan volume pengangkutan.

\section{KESIMPULAN}

Permasalahan sampah anorganik dapat teratasi dengan adanya aktifitas Bank Sampah. Kesadaran masyarakat menjadi factor penting dalam keberhasilan program ini. Dengan adanya penyuluhan, masyarakat akan mengetahui dan memahami bagaimana lingkungan tempat tinggal sangat bergantung pada bagaimana cara kita mengelola lingkungan terutama terkait dengan sampah. Pelatihan diberikan sebagai upaya untuk meningkatkan keterampilan masyarakat dalam mengelola sampah melalui bank sampah. Pendampingan dilakukan untuk mengetahui kendala dan memberikan solusi yang sesuai dengan kebutuhan mitra. Kegiatan pengabdian masyarakat yang dilakukan dapat berjalan dengan baik karena adanya kerjasama dengan perangkat RT, Pengurus bank Sampah serta peran serta masyarakat.

Pengelolaan bank sampah yang baik dapat memberikan manfaat yang signifikan pada masyarakat. Baik secara ekonomi, sosial dan lingkungan. Dengan berbagai manfaat yang bisa dirasakan, maka dengan sendirinya motivasi masyarakat akan muncul dan meningkat. Dengan demikian keberlangsungan bank sampah akan terjaga. Beberapa kegiatan dan capaian dalam pengabdian ini dapat disimpulkan pada tabel 1 berikut. Pengenbangan selanjutnya akan menjadi bahan dalam kegiatan pengabdian yang akan datang.

Tabel 1. Kegiatan dan hasil yang dicapai

\begin{tabular}{lll}
\hline \multicolumn{1}{c}{ Kegiatan } & \multicolumn{1}{c}{ Target } & \multicolumn{1}{c}{ Hasil } \\
\hline Penyuluhan (3R & Mitra/Nasabah & Mitra/Nasabah \\
dan Jenis & memahami jenis- & dapat memilah \\
Sampah) & jenis sampah yang & sampah sesuai \\
& produktif. & jenisnya. \\
\hline Pelatihan (Daur & Mitra memiliki & Mitra mempunyai \\
Ulang dan & ketrampilan daur & produk hasil daur \\
Aplikasi Bank & ulang sampah. & ulang. \\
Sampah) & Mitra bisa & Transaksi Bank \\
& mengoperasikan & Sampah terkelola \\
& software Bank & dengan Baik. \\
& Sampah. & \\
\hline \multirow{2}{*}{ Lingkungan Hidup dan Bencana }
\end{tabular}




\begin{tabular}{|c|c|c|}
\hline $\begin{array}{l}\text { Pendampingan } \\
\text { (Pelaksanaan dan } \\
\text { Tindakan } \\
\text { Perbaikan) }\end{array}$ & $\begin{array}{l}\text { Mitra tidak } \\
\text { mengalami } \\
\text { kesulitan dalam } \\
\text { pelaksanaan } \\
\text { kegiatan. }\end{array}$ & $\begin{array}{l}\text { Kegiatan Bank } \\
\text { Sampah semakin } \\
\text { berkembang dan } \\
\text { bermanfaat. }\end{array}$ \\
\hline Pengembangan & $\begin{array}{l}\text { Peningkatan } \\
\text { produktifitas. } \\
\text { Peningkatan } \\
\text { manfaat. }\end{array}$ & $\begin{array}{l}\text { Rumah } \\
\text { belajar/pintar } \\
\text { (dalam proses). } \\
\text { Mesin pengolah }\end{array}$ \\
\hline
\end{tabular}

\section{UCAPAN TERIMAKASIH}

Terima kasih kami ucapkan kepada Lembaga Penelitian dan Pengabdian Masyarakat (LPPM) dan Fakultas Teknik Universitas Wijaya Putra atas kerjasama dalam penelitian ini.

\section{REFERENSI}

Dwiyanto, BM., (2011). Metode Peningkatan Partisipasi Masyarakat dan Penguatan Sinergi dan Pengelolaan Sampah Perkotaan. Jurnal Ekonomi Pembangunan, Vol. 12, No. 2, desember 2011.

Hadiyanto, dkk., (2011). Pengelolaan Sampah rumah tangga di kecamatan Daha Selatan. Jurnal Ilmu Lingkungan, vol. 9, No. 1 April 2011.

Kusnawati, dkk., (2012). Pemberdayaan Masyarakat Pengelolaan Sampah di Dusun Mrican Sleman. Jurnal Health and Sport. Vol 5. No. 3. Agustus 2012.

Satrio, D. (2018). Bank sampah, program pemerintah Surabaya pendukung "sustainable City". http://www.kompasiana.com. Dikutip 1 april 2019.

Chatarina Regina Soebakti (2016). Penyuluhan dan pelatihan mengolah sampah menjadi dekorasi ruang bagi masyarakat Siwalankerto Surabaya. Prosiding seminar nasional pengabdian masyarakat (sendimas). ISSN 2541-3805, ISSN 2541-559X. plastic. (dalam rencana).

Universitas Kristen Duta Wacana Yogyakarta. 20 oktober 2016. 